\title{
Efeitos da forma física da ração e da linhagem de frangos de corte sobre a digestibilidade dos nutrientes e determinação de energia líquida
}

\author{
[The effects of the physical form of ration and lines of broilers on the digestibility of nutrients \\ and determination of net energy] \\ L.J.C. Lara1, W.E.Campos ${ }^{2}$, N.C. Baião ${ }^{1}$, A.M.Q. Lana ${ }^{1}$, S.V. Cançado ${ }^{1}$, J.S.R. Rocha ${ }^{3}$, \\ M.A. Pompeu ${ }^{3}$, V.M. Barbosa \\ ${ }^{1}$ Escola de Veterinária - Universidade Federal de Minas Gerais - Belo Horizonte, MG \\ ${ }^{2}$ Ministério da Agricultura, Pecuária e Abastecimento (Mapa) \\ ${ }^{3}$ Aluno de pós-graduação - Escola de Veterinária - Universidade Federal de Minas Gerais - Belo Horizonte, MG \\ ${ }^{4}$ Instituto Nacional de Ciência e Tecnologia - INCT- Pecuária
}

\begin{abstract}
RESUMO
Para avaliar os efeitos da forma física da ração, do consumo de ração controlado e das linhagens sobre a digestibilidade dos nutrientes, os valores de energia das rações e a produção de calor pelas aves, foram utilizados 210 pintos machos da linhagem Cobb $^{\circledR}$ e 210 pintos machos da linhagem Ross-308 ${ }^{\circledR}$. Os tratamentos foram definidos pela forma física da ração, pelo consumo de ração controlado e pela linhagem, da seguinte forma: ração farelada à vontade, ração peletizada à vontade e ração peletizada controlada com consumo igual ao da ração farelada. $\mathrm{O}$ delineamento experimental foi o de blocos ao acaso, em arranjo fatorial 3x2 (três rações e duas linhagens), com quatro repetições (períodos), sendo o período considerado como bloco. A digestibilidade da matéria seca não foi afetada pela forma física da ração, entretanto a digestibilidade do extrato etéreo melhorou com a peletização. A linhagem influenciou a digestibilidade dos nutrientes e juntamente com a forma física da ração afetou a produção de calor das aves. A utilização de rações peletizadas aumentou os valores de energia líquida das rações, independentemente da linhagem, favorecendo o desempenho de frangos de corte.
\end{abstract}

Palavras-chave: frango de corte, linhagem, peletização, digestibilidade, produção de calor

\begin{abstract}
The effects of the physical form of the rations on performance and carcass and cut yields of two lines of broilers, Cobb ${ }^{\circledR}$ and Ross ${ }^{\circledR}$ were evaluated. The treatments were defined according to the lines and physical form of the rations and were mash ad libitum, pelleted ad libitum and restricted pelleted (with equal intake of the mash ration). In the trial 420 birds were used, raised in metallic cages adapted for the collection of the excreta. The statistical design was a split plot block in $3 \times 2$ (3 diets and 2 lines) factorial arrangements with 4 repetitions (periods) where the period was considered the block. The digestibility of dry matter was not affected for the physical form of the ration, and the digestibility of the ether extract was enhanced by the peletization. The line affected the digestibility of the rations and with physical form of the ration affect the heat production of the broilers. The use of pelleted rations improved the net energy values of the rations, regardless of the line, enhancing the broilers performance.
\end{abstract}

Keywords: broiler, breeder, peletization, digestibility, heat production

Recebido em 9 de maio de 2012

Aceito em 4 de dezembro de 2012

E-mail: leonardo@vet.ufmg.br 


\section{INTRODUÇÃO}

Os benefícios obtidos com a utilização de rações peletizadas na alimentação de frangos estão relacionados com o menor tempo de ingestão e o menor gasto energético para a mantença (Skinner-Noble et al., 2005), assim como o aumento na digestibilidade dos nutrientes e o melhor aproveitamento destes (GonzalezEsquerra e Leeson, 2000; Svihus et al., 2004). Os efeitos positivos do processo de peletização ocorrem em razão da gelatinização do amido e da melhor digestibilidade das fontes lipídicas, mas esses efeitos podem ser negativos quando a ração é mal processada devido à reação de Maillard (Thomas et al., 1998). Segundo Zelenka (2003), há melhora na digestibilidade da matéria seca, da gordura e aumento na energia metabolizável aparente e aparente corrigida pelo balanço de nitrogênio das rações peletizadas, quando comparadas com rações fareladas.

A energia metabolizável é uma medida útil para avaliar a energia disponível para produção. Entretanto, a energia retida não é utilizada com $100 \%$ de eficiência para crescimento e deposição de tecidos corporais. Durante o processo metabólico, parte da energia é gasta como calor para manutenção da temperatura corporal, em atividades físicas e também no metabolismo dos nutrientes ingeridos, que é o incremento calórico. Este depende da composição química do alimento, além de fatores tais como: consumo e forma física da ração, linhagem, ambiência, atividade física, idade, peso, entre outros (Skinner-Noble et al., 2005).

A energia líquida (EL) é a energia metabolizável menos a energia perdida como calor (incremento calórico) e inclui a energia utilizada para mantença e a energia usada para produção. Portanto, a determinação da EL dos alimentos e das rações, por meio de câmaras respirométricas, e sua influência sobre o metabolismo energético podem resultar em maior eficiência na nutrição dos frangos de corte.

O objetivo deste trabalho foi verificar os efeitos da forma física da ração, do consumo e das linhagens sobre a digestibilidade dos nutrientes e os valores de energia metabolizável aparente, verdadeira e líquida de rações para frangos de corte.

\section{MATERIAL E MÉTODOS}

Para as avaliações da digestibilidade das rações e determinações dos valores das energias metabolizável aparente (EMA), aparente corrigida (EMAn), verdadeira (EMV), verdadeira corrigida (EMVn) e líquida (EL) das rações, foram utilizados 420 pintos de corte, machos das linhagens Cobb $^{\circledR}$ e Ross- $308^{\circledR}$, sendo 210 de cada linhagem. Essas aves foram alojadas em baterias metálicas de $1 \mathrm{~m}^{2}$ cada, equipadas com bandejas próprias para coleta de excretas. Durante a fase inicial (um a 21 dias de idade), foram alojados 15 pintos por bateria. Após esse período, o número foi reduzido para 10 .

Fez-se necessário o alojamento das aves em quatro datas diferentes, com intervalos de 10 dias, para que as avaliações fossem realizadas em frangos da mesma idade, uma vez que a câmara respirométrica utilizada comportava apenas uma bateria. Para efeitos estatísticos, esses intervalos de alojamento foram considerados blocos.

Foram utilizados dois tipos de rações: inicial (de um a 21 dias de idade) e crescimento (de 22 a 36 dias de idade). Em cada fase, as rações diferiramse apenas na forma física (farelada ou peletizada). A composição das rações com os seus valores nutricionais calculados encontramse na Tab. 1. Os níveis nutricionais dos ingredientes seguiram os preconizados por Rostagno et al. (2005), e os níveis nutricionais das rações por Lara et al. (2008).

O diâmetro geométrico médio (DGM) e o desvio padrão geométrico (DPG) foram determinados na ração de crescimento farelada, segundo Zanotto e Bellaver (1996), e o índice de durabilidade do pélete (PDI) foi determinado na ração de crescimento peletizada, conforme American (1997).

Os tratamentos foram definidos pelas linhagens $\left(\mathrm{Cobb}^{\circledR}\right.$ e $\left.\operatorname{Ross}^{\circledR}\right)$, forma física das rações (farelada e peletizada) e consumo da ração peletizada de acordo com o consumo da farelada à vontade. Para se obter o consumo da ração peletizada igual ao consumo da ração farelada, representado pelo tratamento "ração peletizada controlada", dois grupos de 15 pintos, de cada linhagem, foram alojados um dia antes dos demais e alimentados com ração farelada. O consumo médio da ração farelada desses grupos foi calculado diariamente, e esta foi a quantidade oferecida, no dia seguinte, na forma peletizada. 
Tabela 1. Composição percentual e nível nutricional calculado das rações das fases inicial e crescimento

\begin{tabular}{|c|c|c|}
\hline Ingrediente & Inicial & Crescimento \\
\hline Milho & 60,1 & 65,0 \\
\hline Farelo de soja $46 \%$ PB & 25,8 & 10,9 \\
\hline Soja integral tostada & 4,90 & 10,9 \\
\hline Óleo de vísceras & 0,70 & 0,75 \\
\hline F. de carne e ossos $40 \%$ PB & 2,55 & 2,43 \\
\hline Farinha de penas & 1,25 & 4,00 \\
\hline Farinha de vísceras & 3,00 & 4,00 \\
\hline Sal comum & 0,37 & 0,31 \\
\hline DL-Metionina & 0,207 & 0,166 \\
\hline L-Lisina & 0,18 & 0,44 \\
\hline Colina $70 \%$ & 0,066 & 0,055 \\
\hline Suplemento vitamínico/mineral & $0,1^{1}$ & $0,1^{2}$ \\
\hline Fitase & 0,015 & 0,015 \\
\hline Avilamicina & 0,0075 & - \\
\hline Enramicina & - & 0,01 \\
\hline Metil benzoquato/clopidol & 0,05 & - \\
\hline Salinomicina & - & 0,055 \\
\hline Calcário & 0,7045 & 0,8690 \\
\hline Total $(\%)$ & 100,0 & 100,0 \\
\hline \multicolumn{3}{|l|}{ Nível nutricional } \\
\hline Proteína bruta $(\%)$ & 22,5 & 21,0 \\
\hline Energia metabolizável (kcal/kg) & 3050 & 3210 \\
\hline Cálcio (\%) & 0,92 & 0,90 \\
\hline Fósforo disponível (\%) & 0,47 & 0,42 \\
\hline Lisina digestível (\%) & 1,20 & 1,16 \\
\hline Metionina digestível (\%) & 0,50 & 0,43 \\
\hline Metionina + cistina digestível (\%) & 0,78 & 0,75 \\
\hline Sódio $(\%)$ & 0,20 & 0,20 \\
\hline \multicolumn{3}{|c|}{$\begin{array}{l}{ }^{1} \text { Fase inicial: A 13685UI; D3 3157UI; E 35,0mg; K3 4,41mg; B1 2,415mg; B2 8,662mg; B6 5,46mg; B12 } \\
\text { 21,315mcg; biotina 96,25mcg; niacina 53,9mg; ácido fólico 1,228mg; ácido pantotênico 13,86mg; selênio 0,3mg; } \\
\text { iodo 1,0mg; ferro 30mg; cobre 10mg; manganês 90mg; zinco } 80 \mathrm{mg} \text {. } \\
{ }^{2} \text { Fase crescimento: A 9775UI; D3 2255UI; E 25,0mg; K3 3,15mg; B1 1,725mg; B2 6,187mg; B6 3,9mg; B12 } \\
\text { 15,225mcg; biotina 68,75mcg; niacina 38,5mg; ácido fólico 0,87mg; ácido pantotênico 9,9mg; selênio 0,21mg; iodo } \\
\text { 1,0mg; ferro 30mg; cobre 10mg; manganês 90mg; zinco 80mg. }\end{array}$} \\
\hline
\end{tabular}

Durante o período de um a 21 dias de idade, os pintos das duas linhagens foram alimentados de acordo com os tratamentos. O ensaio biológico para as avaliações da digestibilidade de nutrientes e a determinação dos valores de energia pelo método tradicional de coleta total de excretas foi iniciado aos 22 dias de idade, com sete dias de duração, sendo três dias de adaptação, seguidos de quatro dias de coleta de excretas.

As quantidades de rações oferecidas e suas sobras foram pesadas diariamente, e as excretas coletadas e pesadas duas vezes ao dia. No mesmo período de coleta, um lote de dez pintos da mesma idade de cada linhagem foi mantido em jejum por 24 horas, para esvaziamento total do trato gastrintestinal, e suas excretas foram coletadas durante 48 horas para a determinação das perdas metabólicas e endógenas (Albino et al., 1992).

Foram realizadas análises de matéria seca (MS), proteína bruta $(\mathrm{PB})$ e extrato etéreo (EE) e foi determinada a energia bruta da ração e excretas, conforme técnicas descritas por Official... (1995). Os teores de energia bruta foram determinados em bomba calorimétrica adiabática. Os valores de energia metabolizável aparente (EMA), aparente corrigida (EMAn), verdadeira (EMV) e verdadeira corrigida (EMVn) das rações foram calculados utilizando- 
se as equações propostas por Matterson et al. (1965). Com base nos dados de consumo de ração, de produção de excretas e nos resultados das análises laboratoriais, foram calculados os coeficientes de digestibilidade aparente de MS, $\mathrm{PB}$ e EE, de acordo com a fórmula:

$$
\text { Digestibilidade }(\%)=\frac{\text { nutriente ingerido }(\mathrm{g})-\text { nutriente das excretas }(\mathrm{g}) \times 100}{\text { nutriente ingerido }(\mathrm{g})}
$$

Entre 28 e 36 dias de idade, os frangos de cada repetição passaram um dia na câmara respirométrica. A determinação da produção de calor pelas aves foi realizada por meio de calorimetria indireta, ou seja, pela quantidade de energia produzida pela ave na forma de calor, calculada por meio do consumo de $\mathrm{O}_{2}$ e produção $\mathrm{CO}_{2}$, em uma câmara respirométrica de sistema aberto, equipada com aparelho Sable ${ }^{\circledR}$. Essa máquina, a cada cinco minutos, dentro de um período de 24 horas, coletou amostras do ar externo e interno para a determinação das

$$
\begin{gathered}
\mathrm{H}(\mathrm{kj})=16,18 \times \mathrm{O}_{2}(\mathrm{l})+5,02 \times \mathrm{CO}_{2}(\mathrm{l})-5,88 \mathrm{~N}_{\mathrm{u}}(\mathrm{g}) \\
\mathrm{H}=\text { produção de calor; kj = kilojoule; } 1=\text { litro; } \mathrm{N}_{\mathrm{u}}=\text { nitrogênio urinário. }
\end{gathered}
$$

Para o cálculo da produção de calor, foi utilizada a correção em função do balanço de nitrogênio das aves. Os valores utilizados foram provenientes da excreção de nitrogênio das aves em jejum.

O incremento calórico (IC) foi calculado por meio da diferença da produção de calor pelos frangos alimentados menos a produção de calor pelos frangos em jejum (IC $=$ PC alimentado - PC jejum). Para o cálculo da energia líquida (EL) das rações, foram utilizados os valores de energia metabolizável verdadeira corrigida pelo nitrogênio menos o incremento calórico $(\mathrm{EL}=$ EMVn - IC).

A determinação da exigência de energia líquida para mantença foi realizada usando-se as medidas do consumo de $\mathrm{O}_{2}$ e produção de $\mathrm{CO}_{2}$, dos frangos em jejum na câmara respirométrica, durante 24 horas, de acordo com a equação de Brouwer (1965). Antes de entrarem na câmara respirométrica, essas aves foram submetidas a um período de 72 horas de jejum (Chwalibog, 1991). Foram realizadas duas mensurações para cada linhagem, antes e após a entrada dos animais alimentados na câmara respirométrica, utilizando-se 10 aves em cada repetição.

A necessidade de energia metabolizável para mantença $(E M m)$ foi obtida pela divisão da produção de calor da ave em jejum pelo $\mathrm{Km}$ concentrações de $\mathrm{O}_{2}$ e $\mathrm{CO}_{2}$. A concentração máxima permitida de $\mathrm{CO}_{2}$ foi de $0,5 \%$. O consumo de $\mathrm{O}_{2}$ e a produção de $\mathrm{CO}_{2}$ foram calculados baseados no volume e na composição do ar que entrou e que saiu da câmara respirométrica (Chwalibog, 1991). A temperatura da câmara respirométrica foi mantida em $24^{\circ} \mathrm{C}$, controlada por meio de um aparelho de arcondicionado. $\mathrm{O}$ cálculo da produção de calor foi realizado de acordo com a equação de Brouwer (1965):

(constante semelhante à eficiência de uso da energia metabolizável para mantença) de 0,80 (Chwalibog, 1991).

O delineamento experimental foi em blocos ao acaso, em arranjo fatorial $3 \times 2$ (três rações e duas linhagens), com quatro repetições (períodos), sendo o período considerado bloco.

Para avaliar a energia líquida para mantença (ELm) e energia metabolizável para mantença (EMm), foi aplicada a estatística descritiva (média).

Os resultados foram submetidos à análise de variância, e as diferenças entre as médias analisadas pelo teste de Student-Newman-Keuls (SNK). O modelo estatístico utilizado foi o seguinte (Sampaio 2002):

$$
\mathrm{Y}_{\mathrm{ijkl}}=\mu+\mathrm{P}_{\mathrm{i}}+\mathrm{D}_{\mathrm{j}}+\mathrm{L}_{\mathrm{k}}+(\mathrm{DL})_{\mathrm{jk}}+\mathrm{E}_{\mathrm{ijkl}},
$$

$Y_{i j k l}$ - observação do período $i$, da ração $j$, na linhagem k e da repetição 1;

$\mu$ - efeito médio geral;

$\mathrm{P}_{\mathrm{i}}$ - efeito do período $\mathrm{i}$, sendo $\mathrm{i}=1$ a 4 ;

Dj - efeito da ração $\mathrm{j}$, sendo $\mathrm{j}=$ farelada, peletizada e peletizada controlada;

$\mathrm{L}_{\mathrm{k}}$ - efeito da linhagem $\mathrm{k}$, sendo $\mathrm{k}=$ Cobb e Ross;

$\mathrm{DL}_{\mathrm{jk}}$ - efeito da interação entre ração e linhagem; $\mathrm{E}_{\mathrm{ijkl}}$ - efeito do erro aleatório atribuído à observação do período i, na ração j, da linhagem $\mathrm{k}$ na repetição 1 . 


\section{RESULTADOS E DISCUSSÃO}

O DGM e o DPG da ração de crescimento farelada foram de $824 \mu \mathrm{m}$ e de 2,08, respectivamente. Esses valores de DGM estão dentro da faixa preconizada por Nir et al. (1994b) e Ribeiro et al. (2002) para frangos jovens, de 700 a $900 \mu \mathrm{m}$. Menores valores de DPG significam maior uniformidade de partículas. Segundo Nir et al. (1994a), um DPG próximo a dois afeta negativamente o ganho de peso e a conversão alimentar.

O PDI da ração crescimento peletizada foi de 68,5\% de péletes inteiros. Segundo Mckinney e Teeter (2004), aves alimentadas com rações contendo apenas $20 \%$ de péletes íntegros diminuem a preferência e a habilidade para selecionar os péletes, e com $40 \%$ de PDI foram observados ganhos em relação a peso vivo alimentar quando comparadas com rações fareladas.

Os dados de digestibilidade dos nutrientes de acordo com a forma física da ração e linhagem estão apresentados na Tab. 2. Para as variáveis MS, PB e EE, não houve interação entre ração e linhagem. Não houve efeito da forma física, do consumo de ração e da linhagem sobre a digestibilidade da matéria seca $(\mathrm{P}>0,05)$. Resultados semelhantes foram encontrados por López et al. (2007), que comparam a digestibilidade da matéria seca de rações fareladas e peletizadas na fase de crescimento de frangos de corte, com granulometria média de $820 \mu \mathrm{m}$.

Tabela 2. Coeficientes de digestibilidade da matéria seca (CDMS), da proteína bruta (CDPB) e do extrato etéreo (CDEE) das rações (\%) de acordo com a forma física da ração e a linhagem

\begin{tabular}{lccc}
\hline Tratamento & CDMS & CDPB & CDEE \\
\hline Farelada & $79,6 \mathrm{a}$ & $71,6 \mathrm{a}$ & $77,6 \mathrm{~b}$ \\
Peletizada & $79,7 \mathrm{a}$ & $69,3 \mathrm{~b}$ & $89,4 \mathrm{a}$ \\
Peletizada controlada & $79,0 \mathrm{a}$ & $68,9 \mathrm{~b}$ & $89,2 \mathrm{a}$ \\
\hline Cobb & $79,2 \mathrm{a}$ & $68,5 \mathrm{~b}$ & $86,1 \mathrm{a}$ \\
Ross & $79,6 \mathrm{a}$ & $71,3 \mathrm{a}$ & $84,7 \mathrm{~b}$ \\
\hline CV $(\%)$ & 0,81 & 2,40 & 1,88 \\
\hline
\end{tabular}

Médias seguidas de letras diferentes diferem entre si pelo SNK $(\mathrm{p} \leq 0,05)$.

Os frangos que consumiram ração farelada apresentaram melhor digestibilidade da proteína bruta $(\mathrm{P} \leq 0,05)$ do que aqueles que consumiram ração peletizada à vontade e peletizada controlada. Este resultado pode estar relacionado à menor velocidade de passagem das rações fareladas, com granulometria média e grossa, quando comparadas com rações peletizadas, favorecendo a digestibilidade da proteína nas rações fareladas, ou, ainda, com a desnaturação de proteínas ou formação de reações de Maillard em razão do aquecimento a que essas rações são submetidas durante a peletização. Quando se compara a digestibilidade de rações peletizadas com a das fareladas, as variações nas respostas de digestibilidade podem ser atribuídas a diferentes condições de peletização. Provavelmente, a pequena diferença entre o consumo à vontade e o controlado não tenha sido suficiente para alterar a digestibilidade; de acordo com Lara et al. (2008), essa diferença é de aproximadamente $6 \%$.
Os frangos Ross apresentaram melhor digestibilidade da proteína bruta do que os $\mathrm{Cobb}^{\circledR}$. Tal diferença pode estar relacionada à curva de crescimento dessas linhagens e pode levar à alteração na deposição de proteína dependendo da fase em que foi realizado o experimento (Lippens et al., 2002; Marcato et al., 2006a; Lara et al., 2008).

Os frangos alimentados com as rações peletizada e peletizada controlada apresentaram melhor digestibilidade do extrato etéreo $(\mathrm{P} \leq 0,05)$ do que aves alimentadas com ração farelada. Resultados semelhantes foram encontrados por Zelenka (2003). A melhora dessa digestibilidade nas rações peletizadas pode estar relacionada com a maior disponibilidade do óleo intracelular do milho ou, ainda, da soja integral tostada (matérias-primas utilizadas neste experimento), em razão de uma abrasividade maior durante o processo de peletização ou mesmo da destruição de possíveis fatores tóxicos pelo tratamento térmico, levando a um melhor aproveitamento deste nutriente (Gonzalez-Esquerra e Leeson, 
2000). Não foi observado efeito de consumo sobre a digestibilidade do extrato etéreo, pois as aves alimentadas com ração peletizada apresentaram digestibilidade do extrato etéreo semelhante $(\mathrm{P}>0,05)$ à das aves alimentadas com ração peletizada controlada. Comportamento análogo foi verificado na digestibilidade da proteína bruta.

Os frangos $\mathrm{Cobb}^{\circledR}$ apresentaram melhor digestibilidade do extrato etéreo $(\mathrm{P} \leq 0,05)$ em relação aos Ross ${ }^{\circledR}$. Esse resultado também pode estar relacionado com a curva de crescimento e de deposição de nutrientes. Marcato et al. (2006a) observaram que o ponto máximo de deposição de gordura de machos $\mathrm{Cobb}^{\circledR}$ foi aos 49 dias de idade e aos 56 dias de idade para a linhagem Ross $^{\circledR}$, entretanto não encontraram diferenças entre as linhagens em relação à quantidade de gordura depositada.

Os valores calculados de necessidade de energia metabolizável para mantença (EMm) foram os seguintes: $96 \mathrm{kcal} / \mathrm{kg}$ de peso metabólico/dia $\left(\mathrm{kg}^{0,75} /\right.$ dia $)$ para os frangos $\mathrm{Cobb}^{\circledR}$ e $108 \mathrm{kcal} / \mathrm{kg}^{0,75} /$ dia para os frangos Ross ${ }^{\circledR}$. Se for usada a técnica de abate comparativo, a EMm para frangos de corte pode variar de 73 a $163 \mathrm{kcal} / \mathrm{kg}^{0,75} / \mathrm{dia}$ (Nieto et al., 1995). Sakomura et al. (2004), ao trabalharem com a técnica de abate comparativo, encontraram $141 \mathrm{kcal} / \mathrm{kg}^{0,75} /$ dia de energia metabolizável para mantença, determinados em aves entre 22 e 43 dias de idade, para um nível energético da ração de 3.200kcal. Segundo Longo et al. (2006), a exigência de energia para mantença de frangos de corte Ross- $308^{\circledR}$ determinada pela técnica de abate comparativo e por meio de alimentação em diferentes níveis não se alterou em função do nível de alimentação e foi, em média, $135 \mathrm{kcal} / \mathrm{kg}^{0,75} / \mathrm{dia}$, independentemente da temperatura, sendo de $116,2 \mathrm{kcal} / \mathrm{kg}^{0,75} / \mathrm{dia}$ na temperatura de $23^{\circ} \mathrm{C}$. Os menores valores de exigência de energia para mantença encontrados neste experimento podem ser explicados pela utilização de animais em jejum para essa determinação, pois estes apresentam menor atividade física.

A média da produção de calor dos frangos em jejum, ou seja, a necessidade de energia líquida para mantença da linhagem $\mathrm{Cobb}^{\circledR}$, foi de $75 \mathrm{kcal} / \mathrm{kg}$ de peso vivo $/ \mathrm{dia}\left(\mathrm{kg}^{\mathrm{PV}} / \mathrm{dia}\right)$ ou $77 \mathrm{kcal} / \mathrm{kg}^{0,75} / \mathrm{dia}$, e a da linhagem Ross ${ }^{\circledR}$ foi de $83 \mathrm{kcal} / \mathrm{kg}^{\mathrm{PV}} / \mathrm{dia}$ ou $86 \mathrm{kcal} / \mathrm{kg}^{0,75} / \mathrm{dia}$. Essa determinação é importante, pois uma menor necessidade energética para mantença pode levar a um maior ganho de peso em razão da utilização de maiores quantidades de energia para ganho (Skinner-Noble e Teeter, 2003).

Na Tab. 3, são demonstrados os resultados de produção de calor e o incremento calórico das aves sem jejum, de acordo com os tratamentos. Não houve interação entre a forma física das rações e as linhagens.

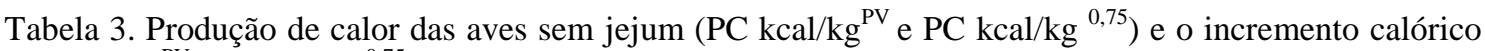
(IC kcal $/ \mathrm{kg}^{\mathrm{PV}}$ e IC kcal $/ \mathrm{kg}^{0,75}$ ) por dia, de acordo com os tratamentos

\begin{tabular}{lcccc}
\multicolumn{1}{c}{ Tratamento } & $\mathrm{PC} \mathrm{kcal} / \mathrm{kg}^{\mathrm{PV}}$ & $\mathrm{PC} \mathrm{kcal} / \mathrm{kg}^{0,75}$ & $\mathrm{IC} \mathrm{kcal} / \mathrm{kg}^{\mathrm{PV}}$ & $\mathrm{IC} \mathrm{kcal} / \mathrm{kg}^{0,75}$ \\
\hline Farelada & 165 & 191 & 86 & 110 \\
Peletizada & 157 & 188 & 79 & 106 \\
Peletizada controlada & 158 & 186 & 80 & 104 \\
\hline Valor de p & 0,31 & 0,22 & $* * *$ & $* * *$ \\
\hline Cobb & 157 & 184 & 82 & 107 \\
Ross & 164 & 192 & 81 & 107 \\
\hline Valor de p & 0,32 & 0,12 & $* * *$ & 0,30 \\
\hline CV $(\%)$ & 7,8 & 5,8 & 15,3 & 12,4 \\
\hline
\end{tabular}

A produção de calor e o incremento calórico das aves por $\mathrm{kg}^{\mathrm{PV}}$ ou $\mathrm{kg}^{0,75}$ não foram afetados pela forma física das rações, pelo consumo, nem pelas linhagens $(\mathrm{P}>0,05)$. A menor produção de calor, em razão da menor movimentação e da facilidade de consumo, para as aves alimentadas com rações peletizadas comparadas a aves alimentadas com ração farelada, pode ter sido mascarada devido ao maior consumo de ração peletizada, o que pode ter colaborado para maior produção de calor (Koh e Macleod, 1999). De acordo com Skinner-Noble e Teeter (2003) e Skinner-Noble et al. (2005), pode haver diferenças na produção de calor entre as 
linhagens, porque estas apresentam diferenças no comportamento, no peso das vísceras e na curva de crescimento. Marcato et al. (2006a,b) encontraram diferenças na curva de crescimento corporal, deposição de nutrientes e peso de órgãos (coração, fígado, proventrículo, moela e intestino) de frangos das linhagens $\mathrm{Cobb}^{\circledR} \mathrm{e}$ $\operatorname{Ross}^{\circledR}$, sendo que a linhagem Ross ${ }^{\circledR}$ apresentou maior crescimento de coração, proventrículo e intestino.

Os valores de energia metabolizável aparente, metabolizável aparente corrigida para nitrogênio, metabolizável verdadeira, metabolizável verdadeira corrigida para nitrogênio e líquida são apresentados na Tab. 4. Não foram observadas interações significativas entre as formas físicas das rações e as linhagens.

Os valores de energia corrigidos pelo balanço de nitrogênio foram, em média, $6 \%$ menores que os valores de EMA e EMV. Tais resultados estão de acordo com Sibbald e Morse (1983) e Leeson e Summers (2001). Segundo esses autores, quando as aves estão em balanço positivo de nitrogênio, os valores de EMAn e EMVn são, aproximadamente, 6 a $7 \%$ menores do que os valores de EMA e EMV.

Tabela 4. Valores de energia metabolizável aparente (EMA), energia metabolizável aparente corrigida para nitrogênio (EMAn), energia metabolizável verdadeira (EMV), energia metabolizável verdadeira corrigida para nitrogênio (EMVn) e energia líquida (EL), na matéria seca, de acordo com os tratamentos em $\mathrm{kcal} / \mathrm{kg}$ de MS

\begin{tabular}{lccccc}
\hline Tratamento & EMA & EMAn & EMV & EMVn & EL \\
\hline Farelada & $3855 \mathrm{~b}$ & $3629 \mathrm{~b}$ & $3866 \mathrm{~b}$ & $3670 \mathrm{~b}$ & $2974 \mathrm{~b}$ \\
Peletizada & $3884 \mathrm{a}$ & $3674 \mathrm{a}$ & $3895 \mathrm{a}$ & $3713 \mathrm{a}$ & $3133 \mathrm{a}$ \\
Peletizada controlada & $3854 \mathrm{~b}$ & $3645 \mathrm{~b}$ & $3865 \mathrm{~b}$ & $3689 \mathrm{ab}$ & $3025 \mathrm{ab}$ \\
\hline Valor de $\mathrm{p}$ & 0,0575 & 0,0529 & 0,0577 & 0,009 & 0,002 \\
\hline Cobb & $3862 \mathrm{a}$ & $3651 \mathrm{a}$ & $3874 \mathrm{a}$ & $3696 \mathrm{a}$ & $3057 \mathrm{a}$ \\
Ross & $3867 \mathrm{a}$ & $3648 \mathrm{a}$ & $3877 \mathrm{a}$ & $3686 \mathrm{a}$ & $3031 \mathrm{a}$ \\
\hline Valor de p & $* * *$ & $* * *$ & $* * *$ & 0,32 & $* * *$ \\
\hline CV $(\%)$ & 0,636 & 0,609 & 0,631 & 0,613 & 3,25 \\
\hline
\end{tabular}

Letras diferentes na coluna diferem entre si pelo $\mathrm{SNK}(\mathrm{P} \leq 0,05)$.

Os valores de EMA, EMAn, EMV, EMVn e EL obtidos com o uso da ração peletizada e consumo à vontade foram superiores $(\mathrm{P} \leq 0,05)$ aos encontrados com a utilização da ração farelada. Também, os valores de EMA, EMAn, EMV com o uso da ração peletizada e consumo controlado foram superiores $(\mathrm{P} \leq 0,05)$ aos encontrados com a ração farelada. Quanto aos valores de EMVn e $E L$, não houve diferença $(P>0,05)$ entre as rações peletizadas à vontade e com o consumo controlado, como também foram semelhantes $(\mathrm{P}>0,05)$ os valores obtidos com as rações fareladas e peletizadas com o consumo controlado. Esses resultados foram semelhantes aos encontrados por Svihus et al. (2004). O aumento dos valores de energia em torno de $1 \%$ pode estar relacionado com maior consumo e melhor digestibilidade de alguns nutrientes (Zelenka, 2003).

A determinação do valor de $3629 \mathrm{kcal} / \mathrm{kg}$ na matéria seca de EMAn da ração farelada se aproxima do valor calculado, que foi de $3590 \mathrm{kcal} / \mathrm{kg}$ na matéria seca ou $3210 \mathrm{kcal} / \mathrm{kg}$ na matéria natural. Ao se observar o valor de $3674 \mathrm{kcal} / \mathrm{kg}$ de EMAn determinado para a ração peletizada, chega-se a um aumento de $45 \mathrm{kcal} / \mathrm{kg}$ de EMAn de matéria seca em razão do processamento.

Foram determinados maiores valores de EL $(\mathrm{P} \leq 0,05)$ nas aves alimentadas com ração peletizada quando comparadas às aves alimentadas com ração farelada. Esse aumento de $5 \%$ de EL pode ser explicado pela melhoria causada no processamento da ração e da facilidade de consumo da ração peletizada pelas aves (Zelenka, 2003; Mckinney e Teeter, 2004). Essa maior energia líquida observada justifica o maior ganho de peso das aves no experimento de desempenho complementar (Lara et al., 2008).

A peletização favoreceu a digestibilidade do EE em relação às rações fareladas e, somada a uma possível melhora no aproveitamento dos carboidratos em razão do calor, da pressão e da umidade do processamento, foi determinante nos 
maiores valores de EMA, EMV e EL encontrados para rações peletizadas.

Os valores de energia, determinados de todas as formas, não foram influenciados $(\mathrm{P}>0,05)$ pela linhagem.

\section{CONCLUSÕES}

O processo de peletização e a linhagem têm efeito sobre a digestibilidade dos nutrientes. A forma física da ração e a linhagem não afetam a produção de calor das aves. A utilização de rações peletizadas aumenta os valores de energia líquida quando comparadas com rações fareladas.

\section{REFERÊNCIAS}

AMERICAN society of agricultural engineers. ASAE S269.4. Cubes, pellets, and crumblesdefinitions and methods for determining density, durability, and moisture. Standards, 1997.

ALBINO, L.F.T.; ROSTAGNO, H.; TAFURI, M.L. et al. Determinação dos valores de energia metabolizável aparente e verdadeira de alguns alimentos para aves, usando diferentes métodos. Rev. Bras. Zootec., v.21, p.1047-1058, 1992.

BROUWER, E. Report of Sub-Committee on Constants and Factors. In: BLAXTER, K.L. Energy Metabolism, London: Academic Press, 1965. p.441-443.

CHWALIBOG, A. Energetics of Animal Production. Acta Agric. Scand., v.41, p.147-160, 1991.

GONZALES-ESQUERRA， R.; LEESON， S. Studies on the metabolizable energy content of ground full-fat flaxseed fed in mash, pellet and crumbled diets assayed with birds of different ages. Poult. Sci., v.79, p.1603-1607, 2000.

KOH, K.; MACLEOD, M.G. Circadian variation in heat production and respiratory quotient in growing broilers maintained at different food intakes and ambient temperatures. Br. Poult. Sci., v.40, p.353-356, 1999.

LARA, J.C.L.; BAIÃO, N.C.; ROCHA, J.S.R. et al. Influência da forma física da ração e da linhagem sobre o desempenho e rendimento de cortes de frangos de corte. Arq. Bras. Med. Vet. Zootec., v.60, p.970-978, 2008.
LEESON, S.; SUMMERS, J.D. Nutrition of the chicken. 4.ed. Ontario: University Books, 2001. 413p.

LIPPENS, M.; HUYGHEBAERT, G.; DE GROOTE, G. The efficiency of nitrogen retention during compensatory growth of foodrestricted broilers. Br. Poult. Sci., v.43, p.669676, 2002.

LONGO, F.A.; SAKOMURA, N.K.; RABELLO, C.B.V. et al. Exigências energéticas para mantença e para o crescimento de frangos de corte. Rev. Bras. Zootec., v.35, p.119-125, 2006.

LÓPEZ, C.A.A.; BAIÃO, N.C.; LARA, L.J.C. et al. Efeitos da forma física da ração sobre a digestibilidade dos nutrientes e desempenho de frangos de corte. Arq. Bras. Med. Vet. Zootec., v.59, p.1006-1013, 2007.

MARCATO, S.M.; SAKOMURA, N.K.; BARBOSA, N.A.A. et al. Curvas de crescimento e da deposição de nutrientes corporais de duas linhagens de frangos de corte. Rev. Bras. Cienc. Avic., v.8, p.167, 2006a.

MARCATO, S.M.; SAKOMURA, N.K.; MUNARI, D.P. et al. Curvas de crescimento dos órgãos de duas linhagens de frangos de corte. Rev. Bras. Cienc. Avic., v.8, p.169, 2006b.

MATTERSON, L.D.; POTTER, L.M.; STUTZ, N.W. et al. The metabolizable energy of feed ingredients for chicken. Storrs, Connecticut: The University of Connecticut, Agricultural Experiment Station, 1965, 11p. (Research Report, 7).

McKINNEY, L.J.; TEETER, R.G. Predicting effective caloric value of nonnutritive factors: I. Pellet quality and II. Prediction of consequential formulation dead zones. Poul. Sci., v.83, p.11651174, 2004.

NIETO, R.; PRIETO, C.; FERNANDEZFÍGARES, I.; AGUILERA, J.F. Effect of dietary protein quality on energy metabolism in growing chicken. Br. J. Nutr., v.74, p.163-172, 1995.

NIR, I.; TWINA, Y.; GROSSMAN, E.; NITSAN, Z. Quantitative effects of pelleting on performance gastrointestinal tract and behavior of meat-type chickens. Br. Poult. Sci., v.35, p.589-602, 1994a. 
NIR, I.; SHEFET, G.; NITSAN, Z. Effect of grain particle size on performance. 2. Grain texture interactions. Poult. Sci., v.73, p.781-791, 1994b.

OFFICIAL methods of analysis of AOAC International. 16.ed. Arlington: AOAC International, 1995.

RIBEIRO, A.M.L.; MAGRO, N.; PENZ JR.; A.M. Granulometria do milho em rações de crescimento de frangos de corte e seu efeito no desempenho e metabolismo. Rev. Bras. Cienc. Avic., v.4, p.1-7, 2002.

ROSTAGNO, H.S.; ALBINO, L.F.T.; DONZELE, J.L. et al. Tabelas brasileiras para aves e suínos - Composição de alimentos e exigências nutricionais. Viçosa: UFV, 2005.

SAKOMURA, N.K.; LONGO, F.A.; RABELLO, C.B.V. et al. Efeito do nível de energia metabolizável da ração no desempenho e metabolismo energético de frangos de corte. Rev. Bras. Zootec., v.33, p.1758-1767, 2004.

SAMPAIO, I.B.M. Estatística aplicada à experimentação animal. 2.ed., Belo Horizonte: FEPMVZ, 2002, 244p.

SIBBALD, I.R.; MORSE, P.M. Effects of the nitrogen correction and of feed intake on true metabolizable energy values. Poult. Sci., v.62, p.138-142, 1983.
SKINNER-NOBLE， D.O.; TEETER， R.G. Components of feed efficiency in broiler breeding stock: energetics, performance, carcass composition, metabolism and body temperature. Poult. Sci., v.82, p.1080-1090, 2003.

SKINNER-NOBLE, D.O.; MCKINNEY, L.J.; TEETER, R.G. Predicting effective caloric value of nonnutritive factors: III. Feed form affects broiler performance by modifying behavior patterns. Poult. Sci., v.84, p.403-411, 2005.

SVIHUS, B.; KLOVSTAD, K.H.; PEREZ, V. et al. Physical and nutritional effects of pelleting of broiler chicken diets made from wheat ground to different coarsenesses by the use of roller mill and hammer. Anim. Feed Sci. Tech., v.117, p.281-293, 2004.

THOMAS, M.; VAN VLIET, T.J.; VAN DER POEL, A.F.B. Physical quality of pelleted animal feed. 3. Contribution of feedstuffs components. Anim. Feed Sci. Tech., v.70, p.59-78, 1998.

ZANNOTO, D.L.; BELLAVER, C. Método de determinação da granulometria de ingredientes para uso em rações de suínos e aves. Local: EMBRAPA, 1996. p. 1-5. (Comunicado técnico).

ZELENKA, J. Effect of pelleting on digestibility and metabolizable energy values of poultry diet. J. Anim. Sci., v.48, p.239-242, 2003. 